\title{
Massive right pleural effusion leading to cardiac tamponade in absence of pericardial effusion: a rare presentation
}

\author{
Kunal Mahajan, Sanjeev Asotra, Prakash Negi, Gunjan Gupta
}

Department of Cardiology, Indira Gandhi Medical College, Shimla, Himachal Pradesh, India

\section{Correspondence to} Dr Kunal Mahajan, kunalmahajan442@gmail.com

Accepted 21 January 2016

\section{DESCRIPTION}

A 40-year-old man with massive right sided pleural effusion was referred for echocardiography to assess ventricular function. His transthoracic echocardiogram revealed a large right pleural effusion. It was causing inversion of the right atrium (figure 1 and video 1 ) in systole and diastole (figure 2), for most of the cardiac cycle. Prolonged right atrial collapse that exceeds one-third of the cardiac cycle is considered $100 \%$ specific and $94 \%$ sensitive for clinical cardiac tamponade. ${ }^{1}$ Notably, there was no pericardial effusion in our patient on echocardiography, which was later also confirmed on CT scan (figure 3). The patient had distension of the veins in his neck and his blood pressure was 90/70 mm Hg. Thoracocentesis was carried out and around $1.5 \mathrm{~L}$ of pleural fluid tapped. Echocardiography was repeated $2 \mathrm{~h}$ later and showed marked improvement in right atrial expansion (figure 4 and video 2). Chest X-ray also demonstrated a decrease in pleural effusion (figure 5) associated with significant improvement in blood pressure.

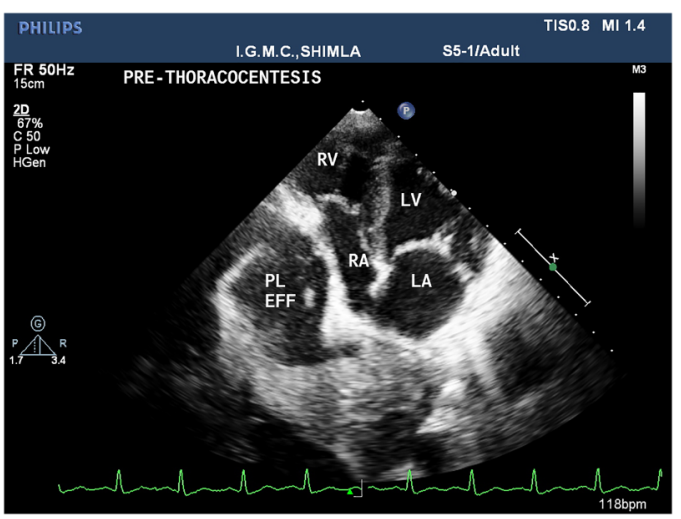

Figure 1 Transthoracic echocardiogram, apical 4-chamber view, demonstrating a large right pleural effusion (PL EFF) causing compression of the right atrium (RA).



Video 1 Transthoracic echocardiogram, apical four-chamber view, demonstrating a large right pleural effusion (PL EFF) causing compression of the right atrium (RA). Note that the compression is present throughout the cardiac cycle.

There are few reports regarding the adverse impact of large pleural effusion on cardiovascular haemodynamics; this condition can manifest as cardiac tamponade. ${ }^{2}$ It is hypothesised that the mechanism of chamber collapse is related to the pleural effusion generating a positive intrathoracic pressure, which in turn causes chamber collapse.

\section{Learning points}

- Prolonged right atrial collapse on echocardiography is a highly specific and sensitive sign for cardiac tamponade, and can be present in conditions other than pericardial effusion

- Large pleural effusions may be associated with signs of cardiac tamponade.

- Thoracocentesis leads to reversal of this clinical picture. 
Figure 2 Right atrial (RA)

compression is noted throughout the cardiac cycle. RA is relatively expanded in early diastole $(A)$ and then progressively compressed late in diastole (B) and in most of systole (C and D).
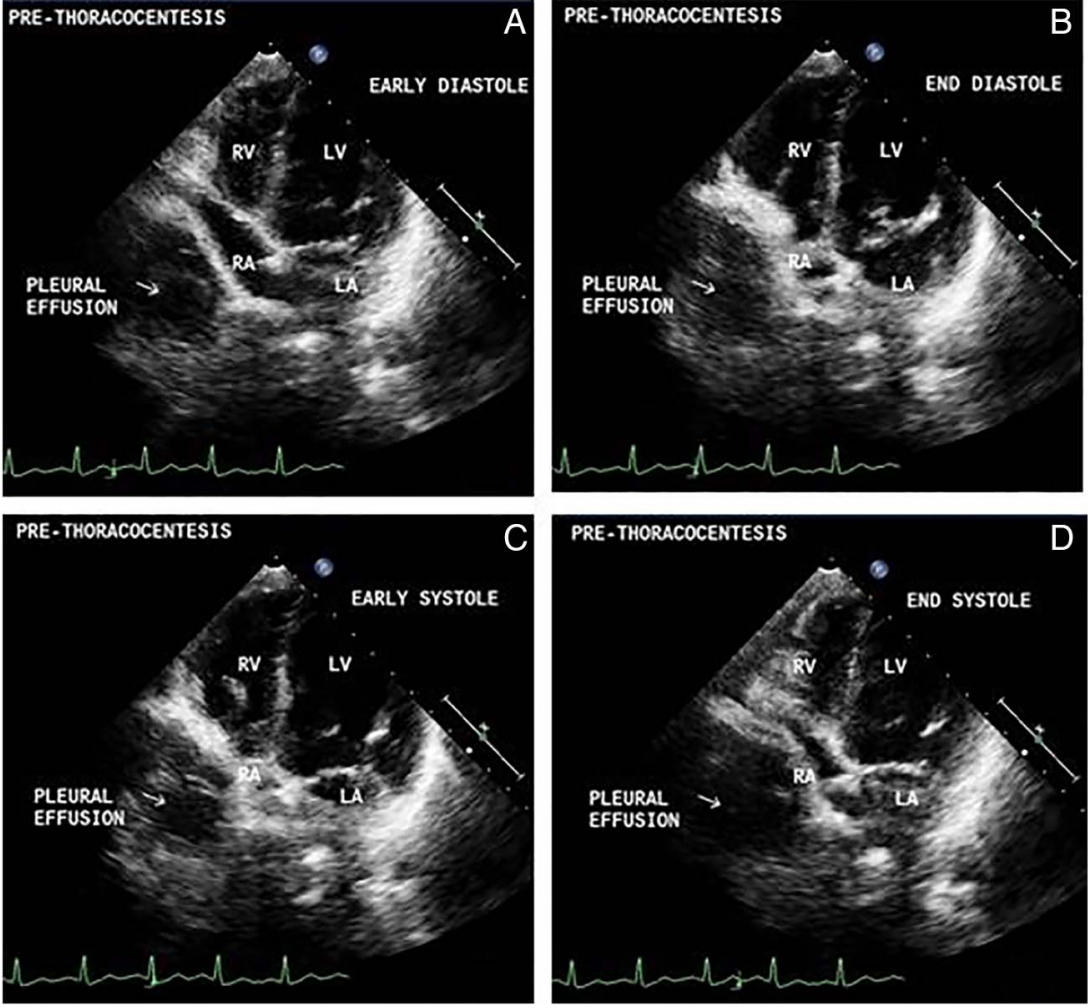

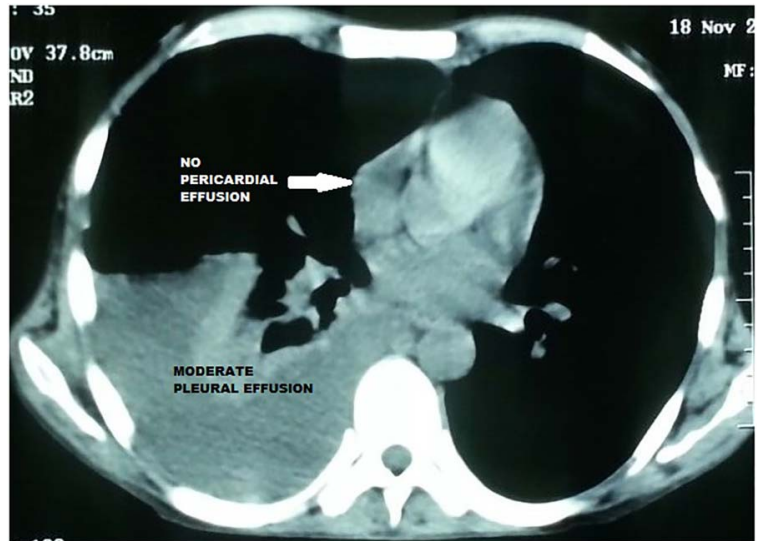

Figure 3 CT of the thorax, axial view, showing moderate right pleural effusion. Note that the left sided pleural cavity is clear and there is no pericardial effusion.

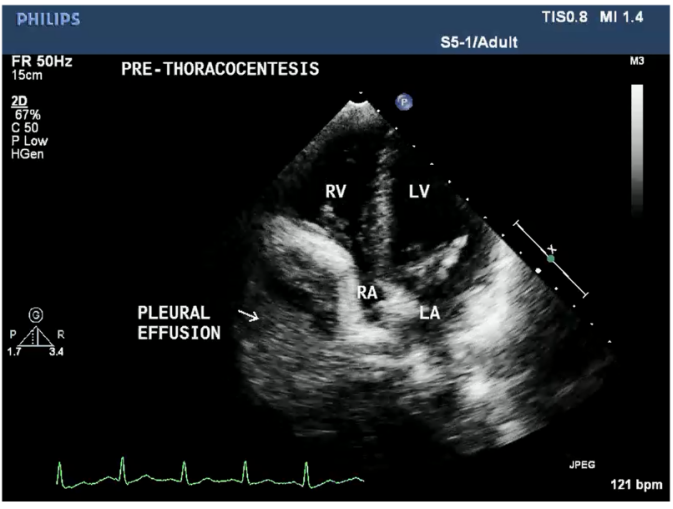

Video 2 Transthoracic echocardiogram, apical four-chamber view demonstrating better expansion of the right atrium (RA) post-thoracocentesis.
Figure 4 Echocardiographic comparison of prethoracocentesis and post-thoracocentesis compression of RA. Note the collapse of RA prethoracocentesis (A), which was relieved post-thoracocentesis (B).
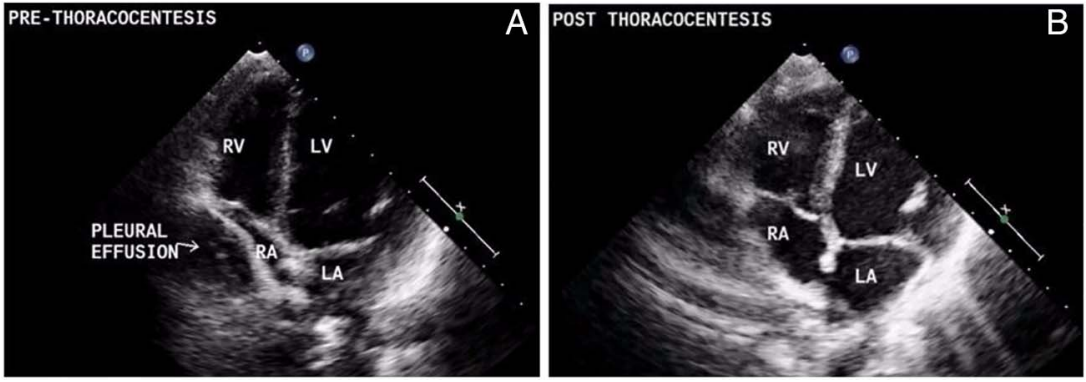
Figure 5 Chest X-ray comparison prethoracocentesis and post-thoracocentesis. (A) Right hemithorax prethoracocentesis. (B) Chest X-ray post-thoracocentesis, still showing massive right pleural effusion.
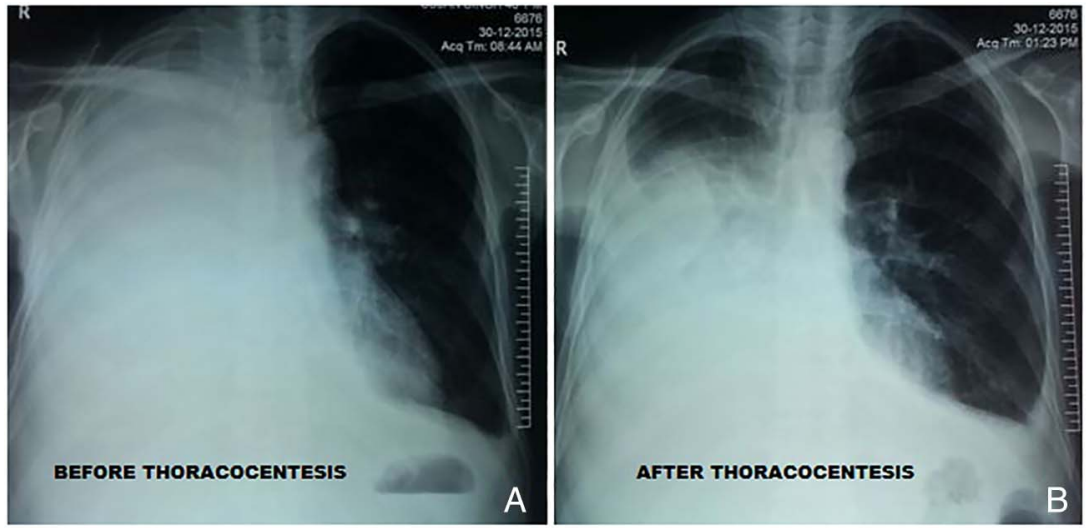

This clinical picture resolves after drainage of the pleural effusion. ${ }^{3}$

\section{REFERENCES}

1 Gillam LD, Guyer DE, Gibson TC, et al. Hydrodynamic compression of the right atrium: a new echocardiographic sign of cardiac tamponade. Circulation 1983;68:294-301.

2 Traylor JJ, Chan K, Wong I, et al. Large pleural effusions producing signs of cardiac tamponade resolved by thoracentesis. Am J Cardiol 2002;89:106-8.

3 Wrisley D. Marked diastolic collapse of the right atrium without hemodynamic compromise caused by large pleural effusion. J Am Soc Echocardiogr 1994;7:87-8.

Patient consent Obtained.

Provenance and peer review Not commissioned; externally peer reviewed.

Copyright 2016 BMJ Publishing Group. All rights reserved. For permission to reuse any of this content visit http://group.bmj.com/group/rights-licensing/permissions.

BMJ Case Report Fellows may re-use this article for personal use and teaching without any further permission.

Become a Fellow of BMJ Case Reports today and you can:

- Submit as many cases as you like

- Enjoy fast sympathetic peer review and rapid publication of accepted articles

- Access all the published articles

- Re-use any of the published material for personal use and teaching without further permission

For information on Institutional Fellowships contact consortiasales@bmjgroup.com

Visit casereports.bmj.com for more articles like this and to become a Fellow 